\title{
Dual flexible endoscopic rendezvous approach for management of a Zenker's diverticulum with complete esophageal obstruction
}

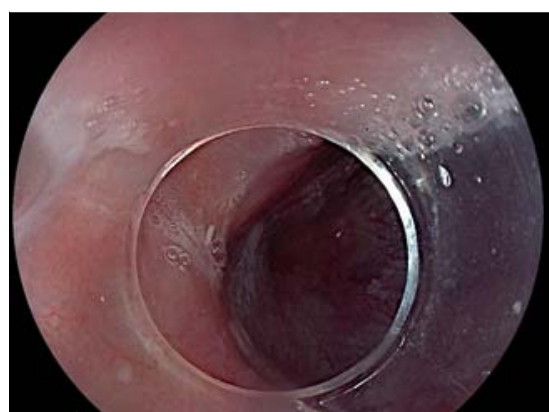

- Fig. 1 View during esophagogastroduodenoscopy showing a large Zenker's diverticulum with complete esophageal obstruction at the level of the cricopharyngeal muscle.

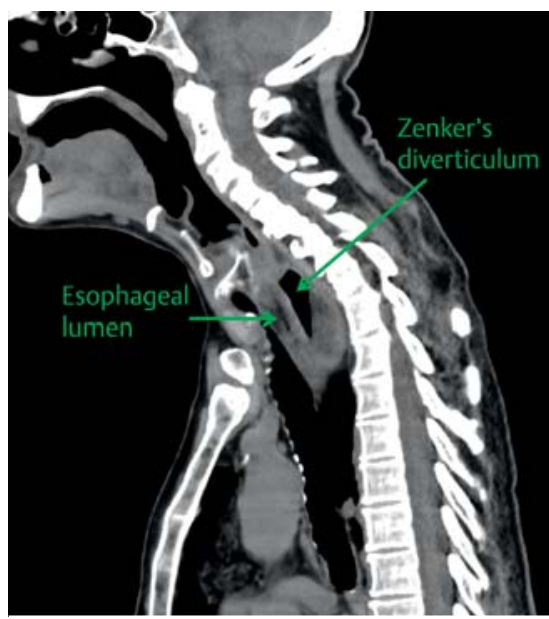

- Fig. 2 Computed tomography scan showing a large diverticulum impinging on the proximal esophagus.

Therapy for symptomatic Zenker's diverticulum has evolved from an open surgical approach to transoral endoscopic techniques using rigid instruments or flexible endoscopes. A recent meta-analysis confirmed that flexible endoscopic myotomy for Zenker's diverticulum is effective and safe [1]. Complete esophageal obstruction is a rare complication that is caused by fusion of the proximal esophageal lumen with the septum of the Zenker's diverticulum [2,3].

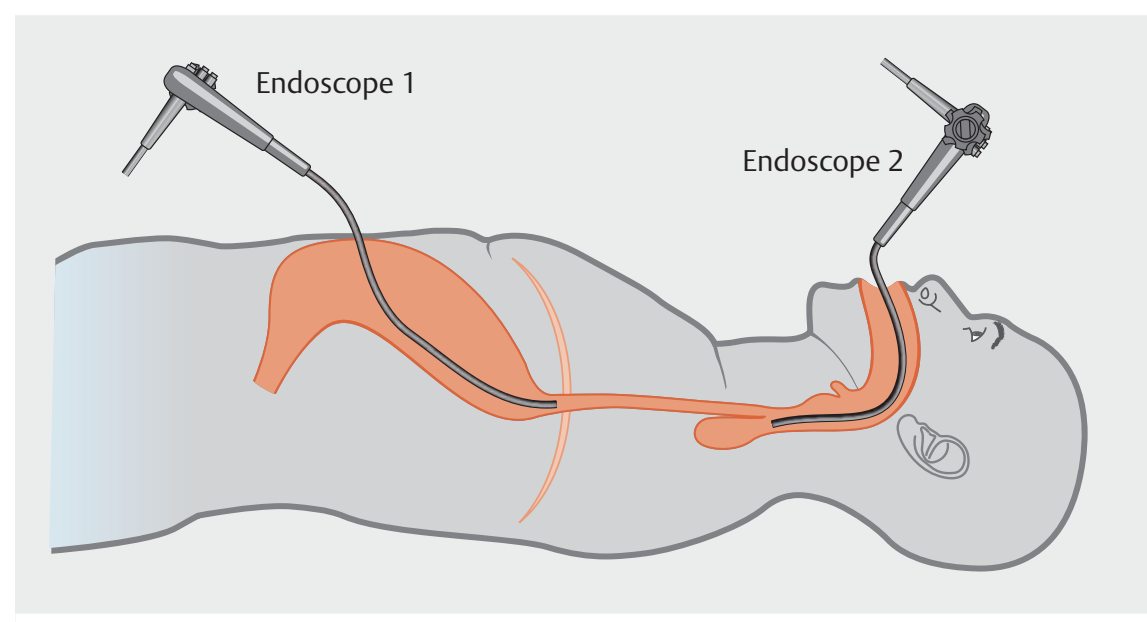

- Fig. 3 Schematic showing the dual endoscopic retrograde-antegrade approach using the established gastrostomy tract and the peroral route that was planned in order to reopen the completely obstructed esophageal lumen and safely perform a flexible endoscopic cricopharyngeal myotomy.
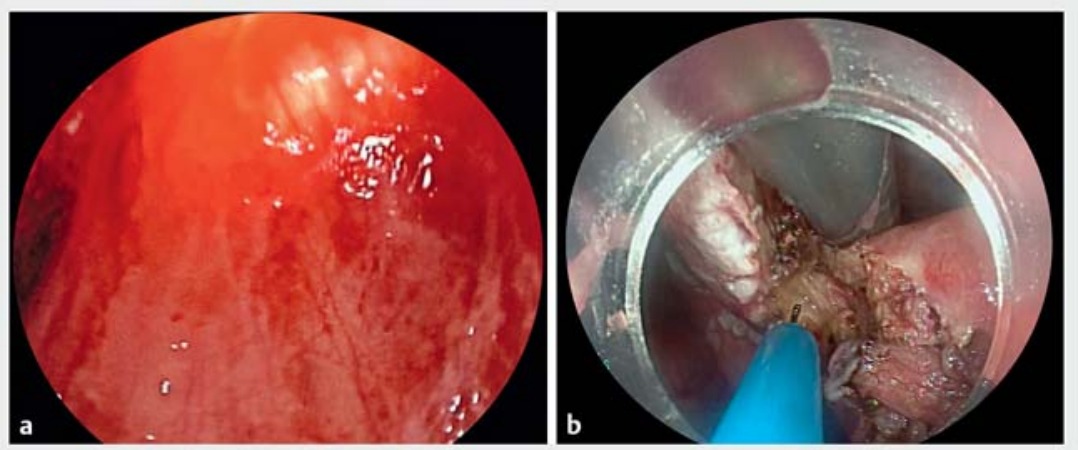

- Fig. 4 Endoscopic views showing: a the two endoscopes being aligned by endoscopic transillumination; $\mathbf{b}$ flexible endoscopic cricopharyngeal myotomy being performed under direct visualization using a hook knife.

We present a case of a 59-year-old man who presented with aphagia with a 7-year history of progressive dysphagia due to a Zenker's diverticulum. A surgical gastrostomy had been created 1 year previously and the patient had been maintained exclusively on enteral nutrition. Esophagogastroduodenoscopy (EGD) and a computed tomography (CT) scan demonstrated a large Zenker's diverticulum with complete esophageal obstruction at the level of the cricopharyngeal muscle suggesting fusion of the esophageal lumen ( $\mathbf{F i g . 1}$ and $>$ Fig. 2). A dual endoscopic retrograde-antegrade approach was planned ( $\triangleright$ Fig. 3 ).

An ultraslim endoscope (5.9-mm diameter; endoscope 1) was introduced through the percutaneous gastrostomy site. A tight distal esophageal stricture was encountered as a consequence of the defunctionalized esophagus, there- 


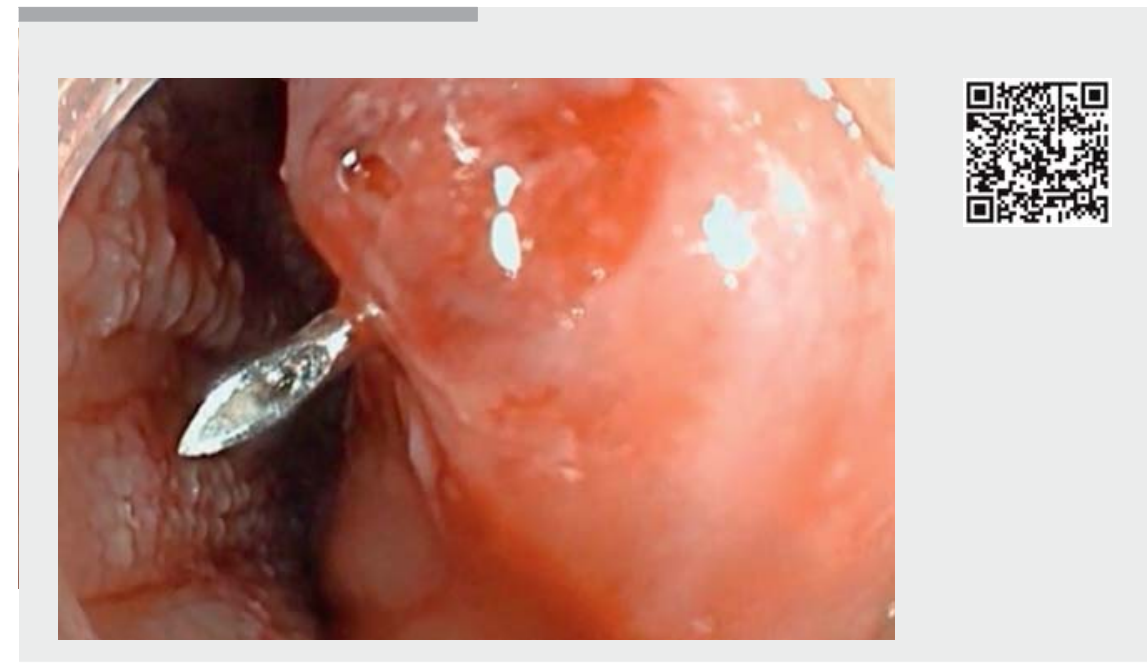

$\checkmark$ Video 1 A dual endoscopic retrograde-antegrade approach for management of a Zenker's diverticulum (ZD) with complete esophageal obstruction.

fore a pneumatic dilation up to $10 \mathrm{~mm}$ was performed ( $\triangleright$ Video 1 ). Subsequently, the endoscope was further advanced in a retrograde fashion up to the proximal esophagus, where a complete esophageal obstruction was confirmed. A peroral endoscope (9.9-mm diameter; endoscope 2) was advanced into the hypopharynx and both endoscopes were aligned by transillumination ( $\triangleright$ Fig. 4 a). Subsequently, retrograde puncture with an injection needle was performed, followed by insertion of a guidewire into the hypopharynx. After capture of the guidewire, a mechanical dilation was performed and a nasogastric tube placed. A flexible endoscopic septotomy was performed 1 week later using a hook knife ( Fig.4b).

After 6 weeks, the patient had gained weight and was eating a regular diet. A barium esophagram and an EGD showed the diverticular pouch was in complete connection with the esophageal lumen. To our knowledge, this is the first reported case of flexible endoscopic septotomy
Corresponding author

\section{Alessandro Fugazza, MD}

Digestive Endoscopy Unit, Division of Gastroenterology, Humanitas Research Hospital, Via Manzoni 56, 20089 Rozzano (Milano), Italy

alessandro.fugazza@humanitas.it

\section{References}

[1] Ishaq S, Hassan C, Antonello A et al. Flexible endoscopic treatment for Zenker's diverticulum: a systematic review and meta-analysis. Gastrointest Endosc 2016; 83: 1076 1089

[2] Shah AT, Wein RO. Management of a postradiation esophageal web in the setting of a coexisting Zenker's diverticulum. Ann Otol Rhinol Laryngol 2013; 122: 775 - 778

[3] Van Twisk J], Brummer RJ, Manni J]. Retrograde approach to pharyngo-esophageal obstruction. Gastrointest Endosc 1998; 48: 296-299

diverticulum after recanalization of complete esophageal obstruction using a dual endoscopic retrograde-antegrade approach. This technique appears to be a promising alternative to surgery in such a complex condition.

Endoscopy_UCTN_Code_TTT_1AO_2AN

\section{Competing interests}

None

The authors

Alessandro Fugazza', Annalisa Cappello', Roberta Maselli' ${ }^{1}$, Paul Belletrutti ${ }^{2}$, Alessia Galtieri ${ }^{1}$, Gaia Pellegatta ${ }^{1}$,

\section{Alessandro Repici ${ }^{1,2}$}

1 Digestive Endoscopy Unit, Division of Gastroenterology, Humanitas Research Hospital, Rozzano, Milan, Italy

2 Humanitas University, Rozzano, Milan, Italy

\section{Bibliography}

DOI https://doi.org/10.1055/a-0894-4324

Published online: 9.5.2019

Endoscopy 2019; 51: E259-E260

(c) Georg Thieme Verlag KG

ISSN 0013-726X

\section{ENDOSCOPY E-VIDEOS \\ https:/|eref.thieme.de/e-videos}

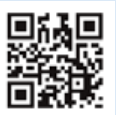

Endoscopy E-Videos is a free access online section, reporting on interesting cases and new techniques in gastroenterological endoscopy. All papers include a high quality video and all contributions are freely accessible online.

This section has its own submission website at https://mc.manuscriptcentral.com/e-videos
Stuttgart · New York 